\title{
Changes in bacteria composition and efficiency of constructed wetlands under sustained overloads: a modeling experiment
}

\author{
Boano F. ${ }^{\mathrm{a}}$, Rizzo A. ${ }^{\mathrm{a}, \mathrm{b}}$, Samsó R. ${ }^{\mathrm{c}}$, García J. ${ }^{\mathrm{d}}$, Revelli R. ${ }^{\mathrm{a}}$, Ridolfi L. ${ }^{\mathrm{a}}$ \\ ${ }^{a}$ Department of Environment, Land and Infrastructure Engineering (DIATI), Politecnico di Torino, Corso Duca degli Abruzzi, 24, 10129 Turin, Italy. \\ ${ }^{b}$ Iridra S.r.l., Via Alfonso la Marmora, 51, 50121 Florence, Italy. \\ ${ }^{c}$ IRSTEA, Freshwater Systems, Ecology and Pollution Research Unit, 5 rue de la Doua, CS70077, 69626, Villeurbanne cedex, France. \\ ${ }^{d}$ GEMMA-Environmental Engineering and Microbiology Group, Department of Civil and Environmental Engineering, Universitat Politcnica de \\ Catalunya-BarcelonaTech, c/ Jordi Girona 1-3, Building D1, E-08034 Barcelona, Spain.
}

\begin{abstract}
The average organic and hydraulic loads that Constructed Wetlands (CWs) receive are key parameters for their adequate long-term functioning. However, over their lifespan they will inevitably be subject to either episodic or sustained overloadings. Despite the consequences of sustained overloading are well known (e.g., clogging), the threshold of overloads that these systems can tolerate is difficult to determine. Moreover, the mechanisms that might sustain treatment efficiency during overloads are not well understood. The aim of this work is to evaluate the effect of sudden but sustained organic and hydraulic overloads on the general functioning of CWs. To that end, the mathematical model BIO_PORE was used to simulate five different scenarios, based on the features and operation conditions of a pilot $\mathrm{CW}$ system: a control simulation representing the average loads; 2 simulations representing $+10 \%$ and $+30 \%$ sustained organic overloads; one simulation representing a sustained $+30 \%$ hydraulic overload; and one simulation with sustained organic and hydraulic overloads of $+15 \%$ each. Different model outputs (e.g., total bacterial biomass and its spatial distribution, effluent concentrations) were compared among different simulations to evaluate the effects of such operation changes. Results reveal that overloads determine a temporary decrease in removal efficiency before microbial biomass adapts to the new conditions and COD removal efficiency is recovered. Increasing organic overloads cause stronger temporary decreases in COD removal efficiency compared to increasing hydraulic loads. The pace at which clogging develops increases by $10 \%$ for each $10 \%$ increase on the organic load.
\end{abstract}

Keywords:

organic load, hydraulic load, buffering capacity, BIO_PORE, CSO

1 Highlights

\section{Acronymes} ones
- Little experimental evidence on the assumed buffering ca- ${ }_{15}^{14}$ pacity of CWs has so far been provided

- Five simulations representing overloading scenarios on $a_{18}$ $\mathrm{HF}$ CW were run

- Hydraulic overloadings have bigger effects than organic ${ }_{21}$

- HF CWs: Horizontal flow constructed wetlands

- HLR: Hydraulic loading rate

- HRT: Hydraulic retention time

- OLR: Organic loading rate

\section{Introduction}

Experience shows that when adequately designed and operated, Horizontal Flow Constructed wetlands (HF CWs) are an efficient and reliable wastewater treatment technology for suspended solids and organic matter removal. The benefits of these systems are maximized when applied to small communities and in places where seasonal population changes may occur [Puigagut et al., 2007; Masi et al., 2007]. CWs are renowned for tolerating relatively high variability of loading rates and influent wastewater quality [Weerakoon et al., 2013]. However a recently published study seems to put limits to this statement [Galvão and Matos, 2012]. Even though complex multi-stage CW systems have been proved to be able to cope with load fluctuations [Ávila et al., 2016], the buffering capacity of singlestage CWs has been generally assumed while little consistent experimental evidence has been provided to show the extent of such capacity.

Several experimental studies exist on the effects of organic and hydraulic loadings, but those studies analyze the response of the system to isolated steady state conditions [e.g., Ojeda et al., 2008], rather than their response when those conditions suddenly change [Galvão and Matos, 2012]. Moreover, inter- 
dependence of HLR and OLR makes it difficult to study the 92 effects of these two operating parameters separately [Galvão ${ }_{93}$ and Matos, 2012]. Examples of those facts are the works 94 of Caselles-Osorio and García [2006] and Weerakoon et al. 95 [2013]. In the first work two identical pilot CWs were used, 96 one fed with glucose and the other fed with starch. Their ex- 97 periment was divided in 4 phases with 2 months duration. Dur- 98 ing each of them, several experimental parameters were varied: 99 presence/absence of sulphate and $\mathrm{NH}_{3}-\mathrm{N}$ in the inflow water, 100 type of water (tap/distilled water), HRT, and inflow COD con-101 centration. On the other hand, Weerakoon et al. [2013] evalu-102 ated the performance of 3 lab scale wetlands (two planted and ${ }_{103}$ an unplanted control) in a tropical region under different HLR $_{104}$ and fed with synthetic wastewater mixed with septage sludge. 105 For all CWs, HLRs were progressively increased from an ini-106 tial value of $2.5 \mathrm{~cm} \mathrm{day}^{-1}$ to $30 \mathrm{~cm} \mathrm{day}^{-1}$, each value being ${ }_{107}$ kept constant for a 12 days. Results from both studies seem ${ }_{108}$ to point to the fact that lower HLRs improve pollutants re-109 moval efficiencies. However, in Weerakoon et al. [2013] the ${ }_{110}$ HLR was linked to the OLR and thus the effects of each could ${ }_{111}$ not be analyzed separately. Although in Caselles-Osorio and ${ }_{112}$ García [2006] the HLR was changed while maintaining a con-113 stant OLR, several other operation parameters were modified ${ }_{114}$ for each of the 4 phases of the study. Moreover, neither of these ${ }_{115}$ studies addresses the adaptation of the systems between chang-116 ing operation conditions, nor they considered the influence of ${ }_{117}$ long-term evolution of the microbial communities over their re-118 sults.

Acknowledging the difficulty of extracting reliable results on $_{120}$ the effects of organic and hydraulic overloadings from the avail-121 able experimental studies, Galvão and Matos [2012] studied the ${ }_{122}$ effects of punctual and sudden organic overloadings on 9 lab $_{123}$ scale HF CWs, divided in 3 different groups (A, B, and C). All ${ }_{124}$ beds were initially batch fed with synthetic wastewater at con-125 stant organic loadings, and the total mass loading was then in-126 creased for 2 weeks while the HLR was unchanged. Although ${ }_{127}$ the mass removal rate increased (indicating an adaptation of the ${ }_{128}$ microbial communities) they observed a general increase in the ${ }_{129}$ effluent COD concentrations and a decrease in the removal effi- 130 ciencies. When the OLR was set back to the initial conditions, ${ }_{131}$ microbial activity and removal efficiencies also went back to 132 match the initial ones. From these results Galvão and Matos ${ }_{133}$ [2012] concluded that, for the organic loads applied in their ${ }_{134}$ study, the buffering capacity of CWs in the short term was not sufficient to absorb the rapidly increasing mass loadings. They also stated that the buffering capacity of CWs is not yet well understood and that further work is required to understand their 136 capacity to adapt to sudden changes of their operating condi-137 tions.

The data from the Galvão and Matos [2012] experiments ${ }_{139}$ were employed by Rizzo et al. [2014] to calibrate a HYDRUS- ${ }_{-140}$ CWM1 model. The calibrated model was later used [Rizzo and ${ }_{141}$ Langergraber, 2016] to investigate the response of the pilot sys-142 tems to sudden changes of influent organic load. In these nu-143 merical experiments, daily sudden loads and two weeks of high ${ }_{144}$ and low load phases were simulated following the European ${ }_{145}$ Standard 12556-3 [2005]. The simulated results suggested $a_{146}$ good buffer capacity of the CW to daily sudden loads. On the other hand, an increase in COD effluent concentration was also predicted during the two weeks of high load due to slow response of anaerobic bacteria. Moreover, the increase in influent organic load led to a longitudinal shift of fermenting bacteria towards the outlet, suggesting that an undersized HF CW could efficiently treat nominal loads but would fail in case of an influent sudden load. These results confirm that duration timescale of overload application significantly affects treatment efficiency.

In order to elucidate the long-term response of CWs to increase in inflow loads, the objective of this work was to evaluate the effect of sudden but sustained organic and/or hydraulic overloads on pollutants removal efficiencies, bacterial communities, and accumulated solids. We also investigated which of the two, either the organic or the hydraulic overloads, has the largest impact on the overall functioning of CWs. To that end, in this work we use a mathematical model called BIO_PORE [Samsó and García, 2013a] which was specifically developed to simulate subsurface-flow Constructed Wetlands general functioning. This model has already been calibrated and used in several works, which have provided new insights on the internal dynamics of CWs and the dynamics of solids accumulation and bacterial growth [Samsó and García, 2013b, 2014].

In this work, five numerical simulations were carried out. First off, the model was run under steady state conditions until bacterial communities and effluent pollutant concentrations reached a noticeable equilibrium. At that point five separate simulations were performed that correspond to four different overloading scenarios and one scenario with no change in inflow load. The simulations involved sudden organic overloads, hydraulic overloads, and both organic and hydraulic overloads at the same time. Each simulation was continued after the sudden inflow load variation until a new equilibrium state was reached. This work puts to tests well accepted beliefs on CWs capacities and provides further insights on their internal functioning and long-term response to operation changes. Moreover, despite in this work we have considered a wetland treating domestic wastewater, the results can be extrapolated to other types of wastewaters and wetland configurations. In particular, the findings of the present study are useful to understand the potential limits of CWs whose performance depends mostly on their short-term buffering capacity.

\section{Methods}

\subsection{The BIO_PORE model}

BIO_PORE is a 2D mechanistic model built in COMSOL Multiphysics ${ }^{\mathrm{TM}}$ software that includes a wide range of physical and biological processes to reproduce the general functioning of CWs [Samsó and García, 2013a]. To that end, it includes fluid flow and transport equations together with the biokinetic model Constructed Wetland Model number 1 (CWM1) [Langergraber et al., 2009]. CWM1 is based on ASM and ADM formulations [Batstone et al., 2002; Henze et al., 2000], and is seen as the most advanced biokinetic model developed for CWs. The wastewater constituents and the bacteria 
groups considered in CWM1 are listed in Table 1. Calibrated values of model biokinetic parameters can be found in Samsó and García [2013a].

\subsection{Simulation strategy}

\subsubsection{System characteristics}

This work analyzes the same domain configuration used by Samsó and García [2013b], who considered a pilot wetland located at les Franqueses del Vallès, Barcelona, Spain [García et al., 2004]. The pilot HF CW has a horizontal area of $54.6 \mathrm{~m}^{2}$ $(10.3 \times 5.3 \mathrm{~m})$, and it is planted with Phargmites australis. It contains a layer of fine gravel $\left(D_{60}=3.5 \mathrm{~mm}\right.$, initial porosity $n=0.4$, hydraulic conductivity $K=50 \mathrm{~m} \mathrm{~d}^{-1}$ ) whose depth varies between $0.6 \mathrm{~m}$ at the inlet and $0.7 \mathrm{~m}$ at the outlet.

Samsó and García [2013b] performed a numerical simulation of the behavior of this HF CW for a period of three years under a constant HLR of $36.6 \mathrm{~mm} \mathrm{~d}^{-1}$ of pre-treated urban wastewater. Results of the simulations at the end of this period showed that effluent concentrations and bacterial biomass within the $\mathrm{CW}$ substantially attained steady-state conditions. This final state after three years is employed as the initial condition at $t=0$ for the simulations presented in this work.

\subsubsection{Numerical simulations}

Five simulations were performed in total. A first simulation ${ }^{201}$ $\left(S_{0}\right)$ was run using the same flow rates and inflow pollutant con- ${ }^{202}$ centrations used by Samsó and García [2013b] for an additional ${ }^{203}$ year of simulation. These flow rates and pollutant concentra- ${ }^{204}$ tions correspond to average values measured in the pilot plant and are summarized in Table 1 . The Table shows that inflow ${ }_{205}$ COD is mainly composed of particulate components $\left(60 \%, X_{S}\right.$ and $\left.X_{I}\right)$ compared to soluble ones $\left(40 \%, S_{F}, S_{A}\right.$, and $\left.S_{I}\right)$. The 206 fraction of inert components $\left(S_{I}, X_{I}\right)$ represents $15 \%$ of total COD. Simulation $S_{0}$ represents normal operation conditions, ${ }_{208}$ in the $\mathrm{CW}$ receives the organic and hydraulic loads for which it ${ }_{200}$ was designed and no overload occurs.

The response of the system to sustained overloads was an- ${ }^{210}$ alyzed by performing four additional simulations in which the inflow is suddenly modified at $t=0$ and it is then kept constant ${ }_{213}$ for one year. The organic and hydraulic overloading considered ${ }_{214}^{213}$ in these four simulations are shown in Table 2. The increase ${ }_{215}$ in organic wastewater loads can be driven by a change in in- ${ }^{215}$ flow pollutant concentration $\left(S^{C}\right)$, hydraulic load $\left(S^{q}\right)$, or both ${ }_{217}^{216}$ $\left(S^{C, q}\right)$. In this study, simulation $S_{+10 \%}^{C}$ and $S_{+30 \%}^{C}$ considered the ${ }_{218}^{217}$ effect of an increase in inflow COD concentration of $+10 \%$ and $_{219}$ $+30 \%$, respectively, without changes in inflow COD fractioning and $\mathrm{NH}_{3}-\mathrm{N}$ concentration. The effect of variations in the $\mathrm{HRT}_{221}$ was investigated by introducing a $+30 \%$ increase in the flow ${ }_{222}$ rate $\left(S_{+30 \%}^{q}\right)$ while keeping all influent concentrations unaltered. ${ }_{223}$ Finally, inflow COD concentration and flow rate were jointly ${ }_{224}$ increased by $+15 \%$ each in simulation $S_{+15 \%,+15 \%}^{C, q}$. It should be ${ }_{225}$ noted that the OLR is the same for simulations $S_{+30 \%}^{C}, S_{+30 \% 226}^{q}$ and $S_{+15 \%,+15 \%}^{C, q}$, and their comparison hence allowed to identify 227 the effect of sustained overloads of equal intensity but caused ${ }_{228}$ by different combinations of contaminant concentrations and ${ }_{229}$ HLRs. The response variables that were analyzed to quantify 230
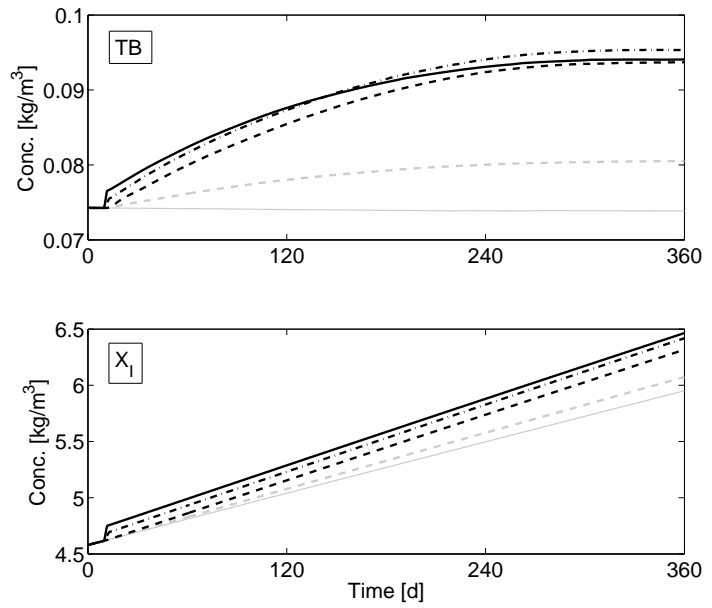

Figure 1: Total biomass (TB - upper panel) and accumulated solid $\left(\mathrm{X}_{\mathrm{I}}\right.$ - lower panel) at the end of the simulation (i.e., after four years of HF-CW functioning) for different influent overload conditions: $+0 \%\left(S_{+0 \%}^{C}\right.$ - gray continuous line), $+10 \%$ and $+30 \%$ of concentrations $\left(S_{+10 \%}^{C}\right.$ - gray dashed line - and $S_{+30 \%}^{C}$ black dashed line, respectively); $+15 \%$ of hydraulic load and $+15 \%$ of concentration $\left(S_{+15 \%,+15 \%}^{C, q}\right.$ - black dash-dotted line $) ;+30 \%$ of hydraulic load $\left(S_{+30 \%}^{q}-\right.$ black continuous line).

the influence of the different overloading scenarios are: spatial distribution in the $\mathrm{CW}$ of the total bacterial biomass and of the main functional groups, COD distribution and fractionation in the $\mathrm{CW}$, effluent concentrations, and removal efficiencies.

\section{Results}

\subsection{Bacterial distribution in the $C W$}

The total amount of bacterial biomass increases with higher inflow mass loads for all simulations. Fig. 1a shows that the simulated total biomass in the $\mathrm{CW}$ increases steadily over time, and that an equilibrium value is attained after one year since the beginning of the overload. The increase in total biomass is very similar for all simulations with a $+30 \%$ increase of OLR $\left(S_{+30 \%}^{C}, S_{+30 \%}^{q}, S_{+30 \%}^{C, q}\right)$. This result indicates that the amount of bacterial biomass at the equilibrium is controlled by the amount of inflow rate of substrate.

The relative abundance of different bacterial groups is summarized in Fig. 2 for the final day of each simulation. This relative abundances refers to the total mass of bacteria in the $\mathrm{CW}$. In all simulations the most abundant groups are sulphate reducers $\left(\mathrm{X}_{\mathrm{ASRB}}\right)$ and fermenters $\left(\mathrm{X}_{\mathrm{FB}}\right)$, followed by methanogens $\left(\mathrm{X}_{\mathrm{AMB}}\right)$. These three groups account for more than $90 \%$ of the total biomass, while heterotrophic bacteria $\left(\mathrm{X}_{\mathrm{H}}\right)$, autotrophic nitrifiers $\left(\mathrm{X}_{\mathrm{A}}\right)$, and sulfur oxidizers $\left(\mathrm{X}_{\mathrm{SOB}}\right)$ are predicted to be scarse because of the aerobic conditions and the absence of nitrate in the inflow (see Table 1). Hence, the discussion about biomass distribution and microbial reactions will hereinafter focus on the prevailing bacterial groups $\mathrm{X}_{\mathrm{ASRB}}, \mathrm{X}_{\mathrm{FB}}$, and $\mathrm{X}_{\mathrm{AMB}}$ because of their leading role in the system.

The presence of bacteria and their distribution in the gravel bed is strongly affected by the inflow characteristics. The com- 


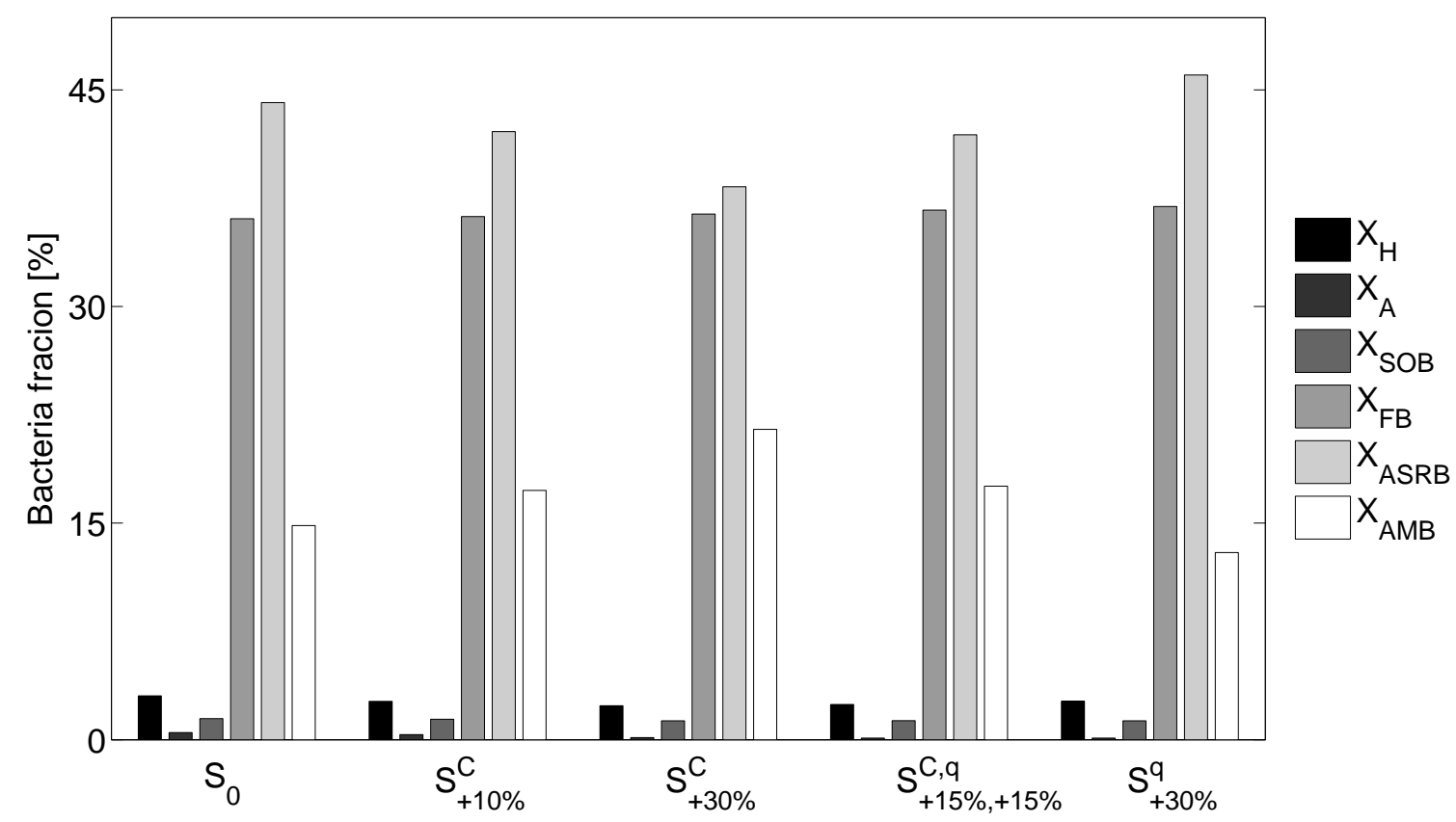

Figure 2: Relative proportion of the total biomass of heterotrophic $\left(\mathrm{X}_{\mathrm{H}}\right)$, autotrophic nitrifying $\left(\mathrm{X}_{\mathrm{A}}\right)$, sulphide oxidising $\left(\mathrm{X}_{\mathrm{SOB}}\right)$, fermenting $\left(\mathrm{X}_{\mathrm{FB}}\right)$, acetotrophic sulphate reducing $\left(\mathrm{X}_{\mathrm{ASRB}}\right)$, and acetotrophic methanogenic $\left(\mathrm{X}_{\mathrm{AMB}}\right)$ bacteria within the $\mathrm{CW}$ at the end of the simulation (i.e., after four years of $\mathrm{HF}-\mathrm{CW}$ functioning) for different influent overload conditions: $+0 \%\left(S_{+0 \%}^{C}\right),+10 \%$ and $+30 \%$ of concentrations $\left(S_{+10 \%}^{C}\right.$ and $S_{+30 \%}^{C}$, respectively); $+15 \%$ of hydraulic load and $+15 \%$ of concentration $\left(S_{+15 \%,+15 \%}^{C, q}\right) ;+30 \%$ of hydraulic load $\left(S_{+30 \%}^{q}\right)$.

parison between $S_{0}, S_{+10 \%}^{C}$, and $S_{+30 \%}^{C}$ in Fig. 2 shows how 259 changes in inflow COD concentration alters the microbial com-260 munity composition. Organic loads with higher COD concen-261 tration result in a slightly lower relative amount of sulphate262 reducers $X_{A S R B}$ and in an increase of methanogenic bacteria ${ }_{263}$ $\mathrm{X}_{\mathrm{AMB}}$. On the other hand, Fig. 2 also reveals that increasing hydraulic load influences the composition of the microbial community differently than increasing inflow COD concentration. The comparison between results of $S_{+30 \%}^{q}, S_{+30 \%}^{C}$, and $S_{+15 \%,+15 \%}^{C, q}$ indicates that shorter HRTs favor the presence of ${ }^{264}$ sulphate reducers over methanogens. All these results about ${ }^{265}$ steady-state contribution of bacterial groups agree very well ${ }^{266}$ with those reported by Ojeda et al. [2008].

The spatial distribution of the most abund nt bacterial group is presented in Fig. 3, which shows the development of a mi-270 crobial zonation within the $\mathrm{CW}$ along the flow direction. The 271 downstream sequence of fermenting bacteria $\left(X_{F B}\right)$, sulphate 272 reducers $\left(X_{A S R B}\right)$, and methanogens $\left(X_{A M B}\right)$ indicates the estab-273 lishment of a longitudinal redox gradient in the $\mathrm{CW}$ that leads to 274 a well defined spatial arrangement of microbial species. Simu-275 lated overloads do not modify the overall biomass zonation but 276 lead to slight changes in the amount and location of the bacterial 277 groups. When inflow COD concentration increases, the area278 occupied by each bacterial group tends to slightly extend in the 279 downstream direction, as shown by the comparison between $S_{0,280}$ $S_{+10 \%}^{C}$, and $S_{+30 \%}^{C}$ in Fig. 3. Instead, if the $+30 \%$ load increment 281 is caused by an increase in hydraulic load $\left(S_{+30 \%}^{q}\right)$ rather than in 282 COD concentration $\left(S_{+30 \%}^{C}\right)$, the simulated results predict little 283 variations in the area occupied by methanogens while sulfate reducers occupy a remarkably wider portion of the CW. The case of an increase in both influent COD concentration and hydraulic load $\left(S_{+15 \%,+15 \%}^{q, C}\right)$ leads to a bacterial distribution within the $\mathrm{CW}$ which is intermediate between $S_{+30 \%}^{C}$ and $S_{+30 \%}^{q}$.

The absence of bacteria in the first part of the CW (see Fig. 3 ) is caused by the progressive accumulation of particulate inert solids $\left(X_{I}\right)$ and biodegradable solids $\left(X_{S}\right)$ that reduce the amount of pore spaces available for biofilm growth [Samsó and García, 2014]. Specifically, simulated results (not shown) indicate that the concentration of inert particles $\left(X_{I}\right)$ is larger by two orders of magnitude than the one of biodegradable particles $\left(X_{S}\right)$, whose accumulation is hence responsible for the clogging of the CW. Fig. $1 \mathrm{~b}$ shows the temporal evolution of the average concentration of accumulated inerts $X_{I}$ for the different simulated overloads. The results show relatively minor differences in the rate of particle accumulation for different overloads over the one year of simulation, thus explaining the similar sizes of clogged areas near the $\mathrm{CW}$ inlet in Fig. 3. A more accurate examination of Fig. $1 \mathrm{~b}$ reveals that the rate of clogging increases of $10 \%$ for every $10 \%$ increase in inflow mass load, which derives from the fact that all influent solid particles are removed by filtration in the $\mathrm{CW}$. This finding implies that clogging induced by the increase in wastewater load would proportionally shorten the lifespan of the considered CW. 

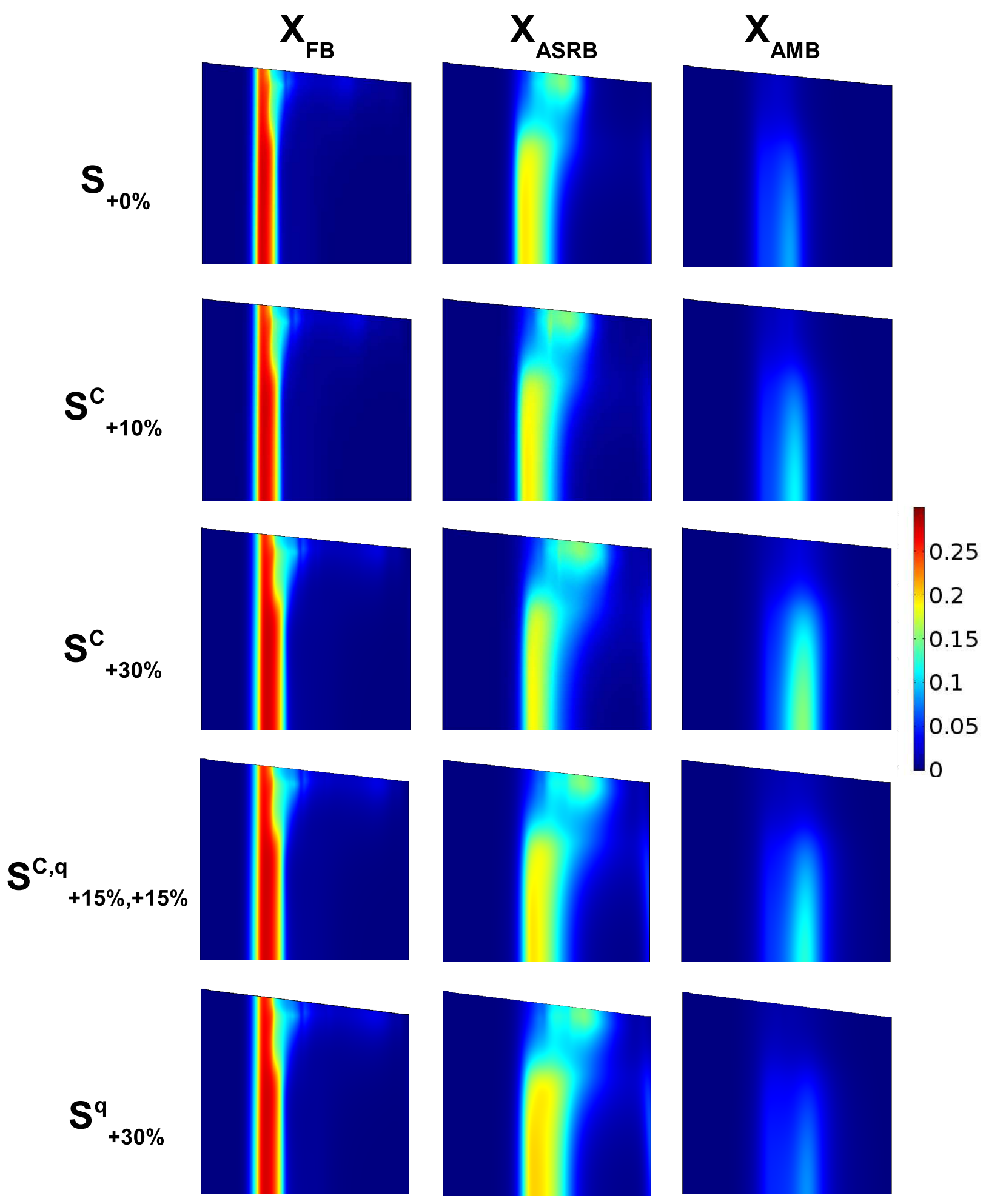

Figure 3: Fermenting $\left(\mathrm{X}_{\mathrm{FB}}\right)$, acetotrophic sulphate reducing $\left(\mathrm{X}_{\mathrm{ASRB}}\right)$, and acetotrophic methanogenic $\left(\mathrm{X}_{\mathrm{AMB}}\right)$ bacteria spatial distribution at the end of simulation (after four years of HF-CW functioning) for different influent overload conditions: $+0 \%\left(S_{+0 \%}^{C}\right),+10 \%$ and $+30 \%$ of concentrations $\left(S_{+10 \%}^{C}\right.$ and $S_{+30 \%}^{C}$, respectively); $+15 \%$ of hydraulic load and $+15 \%$ of concentration $\left(S_{+15 \%,+15 \%}^{C, q}\right) ;+30 \%$ of hydraulic load $\left(S_{+30 \%}^{q}\right)$. Color scale is expressed in $\mathrm{kg} \mathrm{m}^{-3}$ and the longitudinal scale is deformed to facilitate the visualization. 


\section{2. $C O D$ distribution in the $C W$}

The zonation of bacterial biomass in the $\mathrm{CW}$ is mirrored by ${ }^{340}$ the spatial distribution of the different COD components, which ${ }^{341}$ is displayed in Fig. 4 that reports concentration patterns for total ${ }^{342}$ COD and for its reactive components $\left(X_{S}, S_{F}, S_{A}\right)$ at the end of ${ }^{343}$ the one year transient. In all simulations total COD is concen- ${ }^{344}$ trated near the inlet, in accordance with the expected HF $\mathrm{CW}_{345}$ functioning reported in literature [Kadlec and Wallace, 2009].346 The first part of the CW shows no variation in COD concen-347 tration because of the previously discussed absence of bacteria 348 and hence of reactions. It should be noted that this behavior 349 stems from the assumption in BIO_PORE that the wastewater 350 can flow through this clogged area, while wastewater at the in-351 let should flow over this first part of CW gravel bed and infil-352 trate only when the non-clogged part is reached. However, this 353 simplification does has no impact on results on water flow and $_{354}$ reaction rates for the rest of $\mathrm{CW}$. Downstream of the clogged part, fermenting bacteria $\left(X_{F B}\right.$, Fig. 3) first hydrolyze solid biodegradable COD $\left(X_{S}\right)$ into the soluble form $S_{F}$ and then convert it to acetate $\left(S_{A}\right)$ through fermentation (Fig. 4). Acetate is then sequentially degraded by sulphate reducers $\left(X_{A S R B}\right)$ and $_{359}$ methanogens $\left(X_{A M B}\right)$.

When an overload induced by higher COD concentration oc- ${ }^{360}$ curs $\left(S_{0}^{C}\right.$ to $S_{+30 \%}^{C}$, Fig. 4$)$, the total COD concentration in the ${ }_{362}$ $\mathrm{CW}$ increases as well. This increase is particularly evident for acetate $\left(S_{A}\right)$, with the portion of $\mathrm{CW}$ with high acetate con- ${ }_{364}$ centrations extending further downstream with increasing in- ${ }_{365}$ flow COD concentration. While the higher COD availability ${ }_{366}$ enhances growth for all bacterial groups (Fig. 3), the relative predominance of acetate explains the higher presence of methanogens $\left(X_{A M B}\right.$, Figs. 2 and 3 ) compared to other micro- ${ }^{368}$ bial groups. In BIO_PORE, acetate is the substrate used by ${ }^{369}$ methanogenic bacteria $\left(X_{A M B}\right)$ and also by sulphate reducers ${ }^{370}$ $\left(X_{A S R B}\right)$, but the latter also require $\mathrm{SO}_{4}^{2-}$ for their metabolism. ${ }^{371}$ Since inflow concentration of sulphate always remained con- ${ }^{372}$ stant, the growth rate of sulphate reducers did not increase as ${ }^{373}$ much as the one of methanogens.

On the other hand, the proportion of the different COD frac- ${ }^{375}$ tions within the $\mathrm{CW}$ is less sensitive to overloads caused by ${ }^{376}$ increases in HLR compared to increases in COD inflow $\mathrm{COD}^{377}$ concentration. For a $+30 \%$ hydraulic overload, the increase in ${ }^{378}$ total COD and in particular in acetate is less evident than for ${ }^{379}$ organic overloads, as shown by the comparison between $S_{+30 \%}^{C}$, $S_{+15 \%,+15 \%}^{q, C}$ and $S_{+30 \%}^{q}$ in Fig. 4). These small changes in COD fractioning within the $\mathrm{CW}$ explains the relative small variation ${ }^{382}$ in the composition of the bacterial community (Fig. 2 - com- $^{383}$ pare $S_{0}$ and $\left.S_{+30 \%}^{q}\right)$.

\subsection{Effluent concentration}

Variations in COD effluent concentrations over the consid-38s ered period are shown in Fig. 5 (top panel). All simulations ${ }_{389}$ display a transient, with a sharp increase in COD concentration ${ }_{390}$ shortly after the beginning of the overload. COD concentra-391 tions peak after approximately after 45-60 days of overload,392 and then decrease to values $\left(22.3-24.3 \mathrm{mg} \mathrm{l}^{-1}\right)$ that are close 393 the the original one after almost one year. The existence of this ${ }_{394}$ transient shows that the $\mathrm{CW}$ requires a considerable amount of time before it can effectively treat the increased load. The maximum peak concentrations occur for the $+30 \%$ mass overloads and is highest for simulation $S_{+30 \%}^{C}$, followed by $S_{+15 \%,+15 \%}^{C, q}$ and $S_{+30 \%}^{q}$. Increases in concentration are hence more critical than increases in flow rate.

The fractionation of the effluent is shown in Fig. 6 for the final steady configuration. Total effluent COD is essentially composed of inert soluble COD $\left(S_{I}\right)$ and acetate $\left(S_{A}\right)$, plus negligible amounts of fermentable COD $\left(S_{F}\right)$ which has mostly been converted into acetate (see Fig. 4). Particulate components $\left(X_{S}, X_{I}\right)$ are absent after having completely been filtered out by the CW. Overload conditions increase the proportion of acetate $\left(S_{A}\right)$. This increase is slightly higher when the overload is caused by an increase in HLR (compare $S_{+30 \%}^{C}, S_{+15}^{C, q}$ and $S_{+30 \%}^{q}$ in Fig. 6).

Effluent concentrations of Total Nitrogen (TN) are displayed in Fig. 5 (center). After a sharp increase that is similar to the increase in COD concentration, TN effluent concentration do not show any decrease and instead stabilize to a constant value. This equilibrium value ranges 53.7 and $55.9 \mathrm{mg} \mathrm{l}^{-1}$ in the case of a $+10 \%$ and $+30 \%$ overload, respectively. The HF CW is unable to manage the increased amount of $\mathrm{TN}$ - mostly composed of $\mathrm{NH}_{4}^{+}$- because the competition for dissolved oxygen results in a marginal presence of autotrophic nitrifiers $\left(X_{A}\right)$, which are outcompeted by heterotrophic bacteria $\left(X_{H}-\right.$ Fig. 2$) . \mathrm{NH}_{4}^{+}$ hence cannot be oxidized to nitrate for further denitrification, and it is transferred as TN to the CW outlet with almost no removal.

Fig. 5 (bottom panel) show sulphate concentrations at the $\mathrm{CW}$ outlet. Overload conditions enhance $\mathrm{SO}_{4}^{2-}$ removal for all simulations. The decrease in $\mathrm{SO}_{4}^{2-}$ effluent concentration reflects the development of acetotrophic sulphate reducing bacteria $\left(\mathrm{X}_{\mathrm{ASRB}}\right.$, see Fig. 3) driven by increased availability of organic carbon in the $\mathrm{CW}$. Sulphate removal hence improves for more intense overloads, as demonstrated by the comparison between $S_{+10 \%}^{C}$ and $S_{+30 \%}^{C}, S_{+15 \%,+15 \%}^{C, q}$, and $S_{+30 \%}^{q}$ ) in Fig. 5 .

Removal efficiency of COD and TN are presented in Fig. 7. COD removal efficiency is equal to $91 \%$ before the beginning of the overload, and then varies in the range between $85 \%$ and 93\% depending on the considered overload simulation. Efficiencies at the end of the simulation are equal or even higher than at the beginning. However, the time required to recover from the transient efficiency drop is high due to the slow growth rates of anaerobic bacterial groups. This behavior results in a long transition phase (almost six months) in which COD removal efficiency is lower and potentially insufficient to ensure the design effluent concentrations. Organics overloads induce strongest fluctuations in COD removal efficiencies, but they also exhibit shorter recovery times compared to hydraulic overloads (compare $S_{+30 \%}^{C}$ and $S_{+30 \%}^{q}$ in Fig. 7, upper panel). TN removal efficiencies (Fig. 7 - lower panel) always decrease in presence of overloads because of the previously discussed limits of the $\mathrm{HF} \mathrm{CW}$ in efficiently removing $\mathrm{NH}_{4}^{+}$and of the resulting higher TN effluent concentrations (Fig. 5 - central panel). Efficiency in TN removal drop from $21 \%$ before the overload 

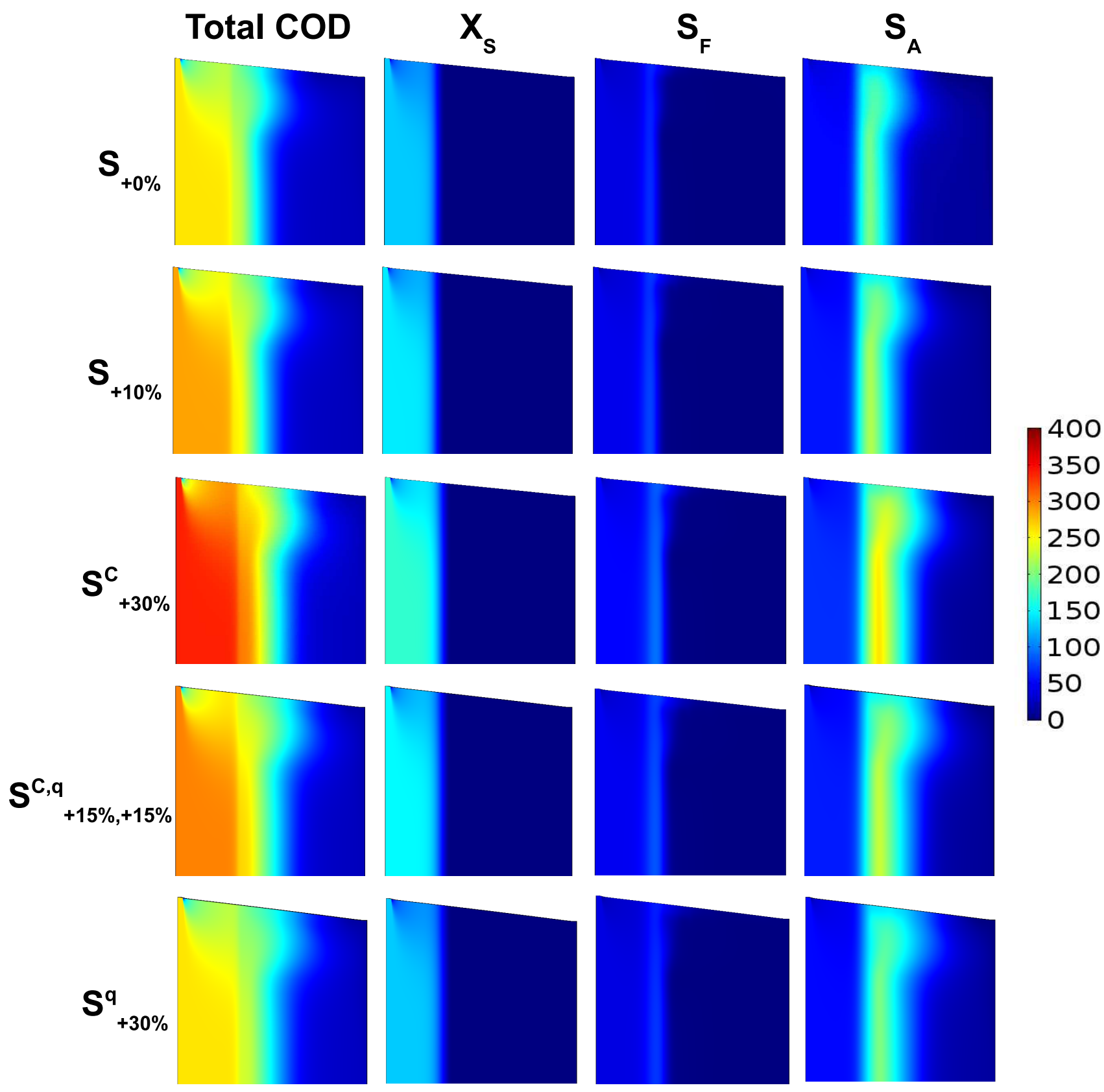

Figure 4: Total, slowly biodegradable particulate $\left(\mathrm{X}_{\mathrm{S}}\right)$, fermentable readily biodegradable $\left(\mathrm{S}_{\mathrm{F}}\right)$, fermentation products as acetate $\left(\mathrm{S}_{\mathrm{A}}\right)$ COD spatial distribution at the $360^{\text {th }}$ day of simulation (end of the fourth year of HF-CW functioning) for different influent overload conditions: $+0 \%\left(S_{+0 \%}^{C}\right),+10 \%$ and $+30 \%$ of concentrations $\left(S_{+10 \%}^{C}\right.$ and $S_{+30 \%}^{C}$, respectively); $+15 \%$ of hydraulic load and $+15 \%$ of concentration $\left(S_{+15 \%,+15 \%}^{C, q}\right) ;+30 \%$ of hydraulic load $\left(S_{+30 \%}^{q}\right)$. Colour scale is expressed in $\mathrm{mg} 1^{-1}$ and the longitudinal scale is deformed to facilitate the visualization. Note as well that Total COD corresponds to the sum of $\mathrm{S}_{\mathrm{F}}, \mathrm{S}_{\mathrm{A}}, \mathrm{S}_{\mathrm{I}}, \mathrm{X}_{\mathrm{S}}$ and $\mathrm{X}_{\mathrm{I}}$. 

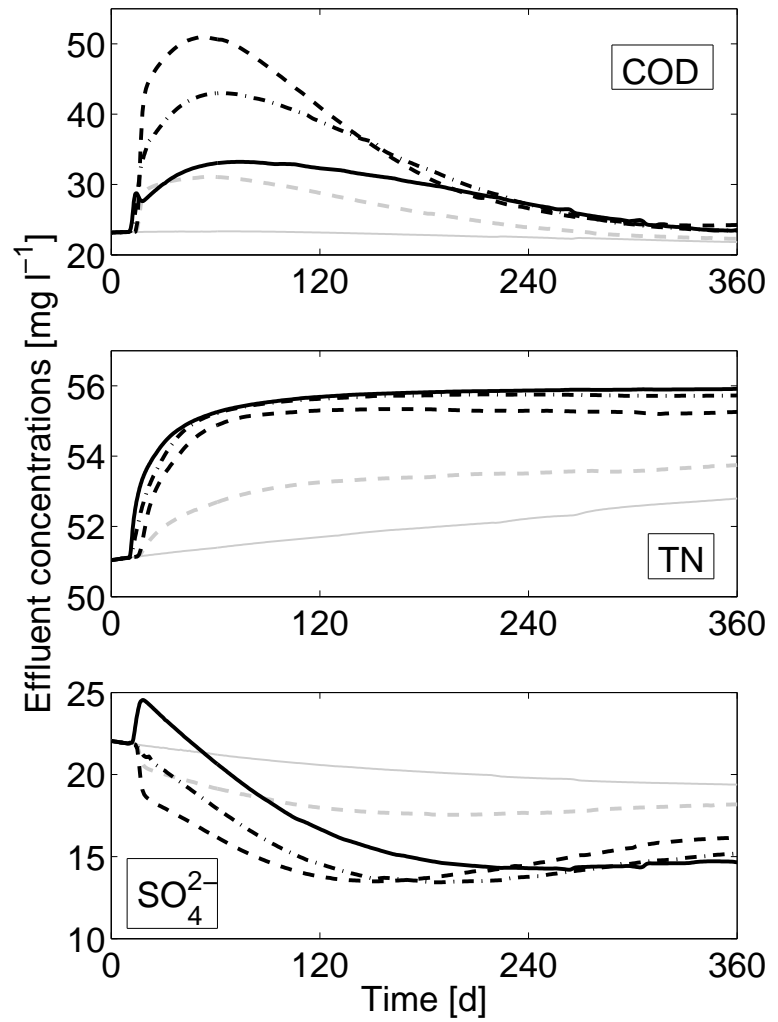

Figure 5: Effluent concentration of COD (upper panel), total nitrogen $\left(\mathrm{S}_{\mathrm{NH}}+432\right.$ $\left.\mathrm{S}_{\mathrm{NO}}\right)\left(\mathrm{TN}-\right.$ middle panel), and sulphates $\left(\mathrm{SO}_{4}{ }^{2-}\right)$ during the $360^{\text {th }}$ day of $\operatorname{sim}^{-}{ }_{433}$ ulation (i.e., during fourth year of HF-CW functioning) for different influent overload conditions: $+0 \%\left(S_{+0 \%}^{C}\right.$ - gray continuous line), $+10 \%$ and $+30 \%$ of $^{434}$ concentrations $\left(S_{+10 \%}^{C}\right.$ - gray dashed line - and $S_{+30 \%}^{C}$ - black dashed line, re- ${ }^{435}$ spectively); $+15 \%$ of hydraulic load and $+15 \%$ of concentration $\left(S_{+15 \%+15 \%}^{C, q}\right.$ - black dash-dotted line); $+30 \%$ of hydraulic load $\left(S_{+30 \%}^{q}\right.$ - black continuous ${ }^{437}$ line). to values ranging between $13 \%\left(S_{+30 \%}^{q}\right)$ and $17 \%\left(S_{+10 \%}^{C}\right)$. Increase in HLR are more critical in terms of TN removal efficiency compared to increases in inflow concentration.

\section{Discussion}

Simulation results from the present numerical analysis show

$$
\text { resp }
$$
that sustained organic and hydraulic overloads produce a transient in the functioning of the $\mathrm{CW}$, with temporarily higher effluent concentrations and lower removal efficiencies. This transient occurs because the amount of bacterial biomass is not suited to the modified biochemical conditions induced by the overloads, and almost one year is required for bacteria to adapt to the new conditions considered in this study. During this transient, overloads due to increases in inflow concentration determine high nutrient concentration within the $\mathrm{CW}$ that the initial amount of bacteria cannot fully metabolize. Overloads due to increases in HLR instead reduce contact times between nutrients and microbial biomass and hence decrease removal efficiencies. In both cases, total bacterial biomass in the CW increases, with slight modifications in its composition, and $\mathrm{CW}$ performance in COD removal increases back to values similar or higher than the original ones. The same behavior occurs for $\mathrm{SO}_{4}^{2-}$ removal, while efficiencies in total nitrogen decrease because the competition for dissolved oxygen among bacterial groups limits the growth of nitrifying bacteria.

The simulated scenarios considered a set of overload configurations in which COD concentrations and HLR have been independently varied after three years of constant load. For domestic wastewater, changes in influent COD concentration may be caused by the introduction of water saving techniques and practices [Marleni et al., 2015] as well as by variations in primary treatment, while variations in HLR may derive from the increase in population equivalents (e.g., variations in the number of residents). The present results provide insights on the effect of sustained overloads that can be helpful even for situations in which both concentrations and HLR are changed. However, it is important to stress that the present study has always considered the same composition of inflow COD, and the CW response to overloads is likely to be affected by COD fractionation. Differences in COD fractionation would impact the rate composition of the bacterial community (Fig. 2). Nonetheless,
we expect that the qualitative picture here discussed will still be
valid, even though some quantitative changes are expected. folid accumulation and clogging (Fig. 1) and the relative valid, even though some quantitative changes are expected.

The findings of the present work are coherent with previous numerical studies [Ojeda et al., 2008] on the steady state conditions developed in CWs after changes in inflow wastewater loads, with effluent COD concentrations increasing in response to increases in either inflow COD concentrations or HLR. The present results are also in line with those obtained from the laboratory experiments performed by Galvão and Matos [2012], who also observed a decrease in COD removal efficiency after the application of an overload. However, the study was focused on the effects of overloads with a short duration (i.e., two weeks), a period that did not allow for bacterial species to reach a new steady condition and for the $\mathrm{CW}$ to recover its original 


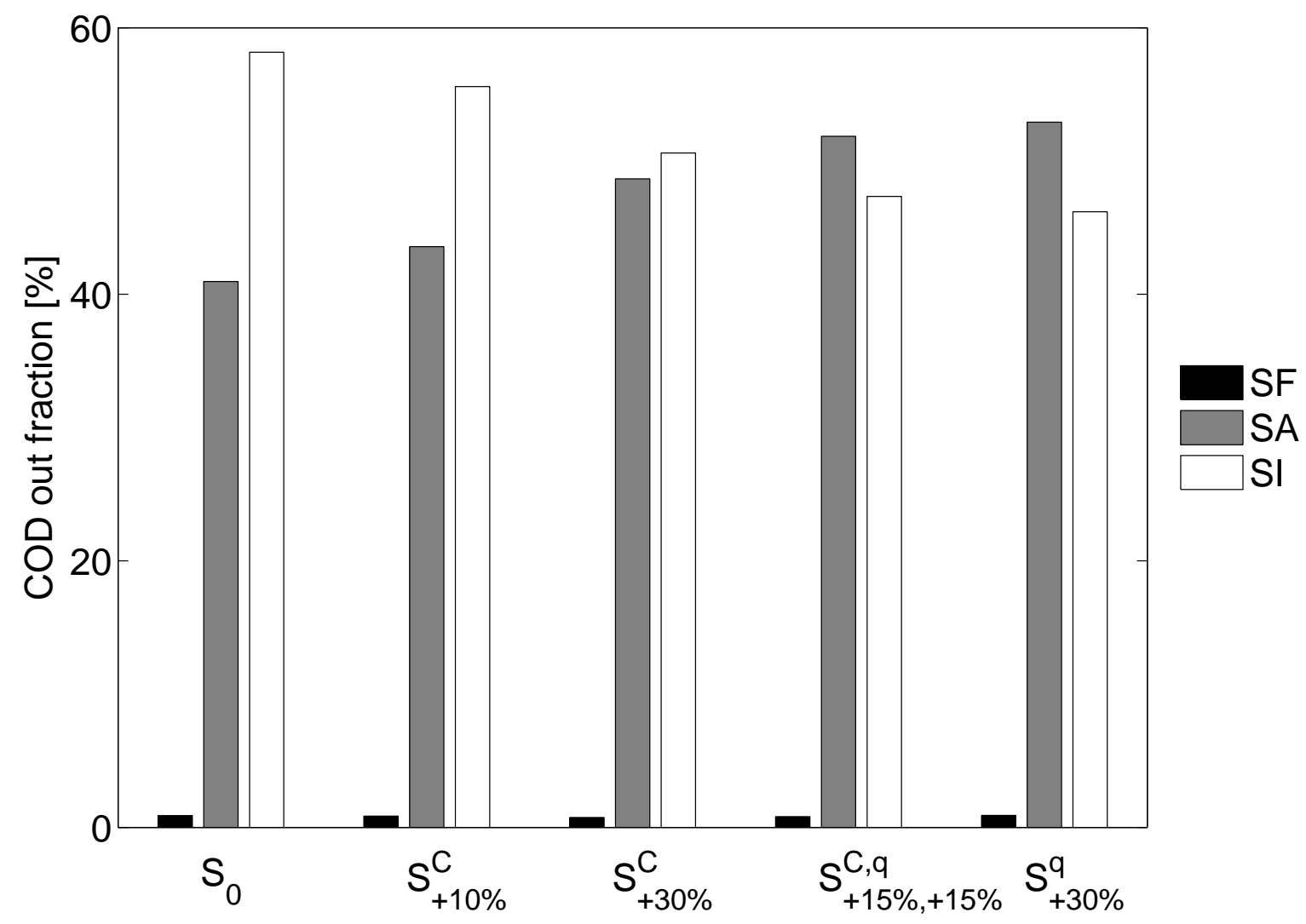

Figure 6: Relative fraction of fermentable readily biodegradable $\left(\mathrm{S}_{\mathrm{F}}\right)$, acetate fermentation products $\left(\mathrm{S}_{\mathrm{A}}\right)$, and inert soluble $\left(\mathrm{S}_{\mathrm{I}}\right)$ effluent COD concentration during the $360^{\text {th }}$ day of simulation (i.e., during fourth year of HF-CW functioning) for different influent overload conditions: $+0 \%\left(S_{+0 \%}^{C}\right),+10 \%$ and $+30 \%$ of concentrations $\left(S_{+10 \%}^{C}\right.$ and $S_{+30 \%}^{C}$, respectively); $+15 \%$ of hydraulic load and $+15 \%$ of concentration $\left(S_{+15 \%,+15 \%}^{C, q}\right) ;+30 \%$ of hydraulic load $\left(S_{+30 \%}^{q}\right)$. 

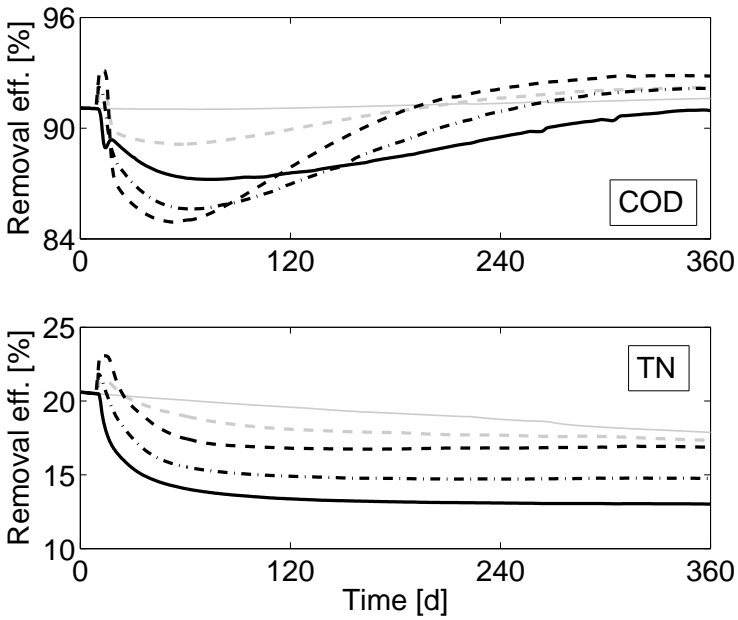

Figure 7: Removal efficiency of COD (upper panel) and total nitrogen (TN lower panel) during the $360^{\text {th }}$ day of simulation (i.e., during fourth year of HF$\mathrm{CW}$ functioning) for different influent overload conditions: $+0 \%\left(S_{+0 \%}^{C}\right.$ - gray continuous line), $+10 \%$ and $+30 \%$ of concentrations $\left(S_{+10 \%}^{C}\right.$ - gray dashed line - and $S_{+30 \%}^{C}$ - black dashed line, respectively); $+15 \%$ of hydraulic load and + $15 \%$ of concentration $\left(S_{+15 \%,+15 \%}^{C, q}\right.$ - black dash-dotted line $) ;+30 \%$ of hydraulic load $\left(S_{+30 \%}^{q}\right.$ - black continuous line).

removal efficiency. Our results indicate that sustained overloads are less critical than relatively frequent variations in organic load. The findings of the present study are useful to describe the evolution of $\mathrm{CW}$ performance during the transient between a sudden change in inflow load and the establishment of new equilibrium conditions.

\section{Conclusions}

The numerical simulations described in the present work has shown the response of a HF CW to sustained hydraulic and organic overloads. The simulation results provide insights on the buffer capacity of CWs that have to deal with such variations in inflow wastewater load. The common claim about $\mathrm{CW}$ efficiency in treating organic loads is generally confirmed, as the simulation results show that the considered overloads cause a moderate drop in COD removal efficiency, which is never lower than $85 \%$ (compared to an original $91 \%$ value before the overload application) for a $+30 \%$ overload condition. Hence, even though the adaptation to the new load conditions is slow, the CW always exhibits a rather high COD treatment performance. After the microbial biomass in the $\mathrm{CW}$ has fully adapted to the new conditions, the system eventually shows a slight improvement in removal efficiency compared to pre-overload conditions.

Despite the capacity of the HF CW to effectively manage increases in wastewater inflow, the present findings indicate that some caution should be exercised to verify that higher COD effluent concentration during the transient does not negatively affect the receiving water body. The occurrence of overloads with relatively short duration that prevent adaption of the microbial groups is particularly critical because the $\mathrm{CW}$ would be unable to recover the original efficiency. An additional problem is that the ability of the $\mathrm{CW}$ to cope with organic overloads is coupled with a reduction of the $\mathrm{CW}$ lifespan due to the increased rate of clogging [Samsó and García, 2014]. Although the CW successfully remove the increased inflow of suspended particle, this effectiveness entails that the clogging rate increases proportionally to the increase in organic load. The impact of the increased clogging rate on the $\mathrm{CW}$ lifespan should thus be carefully considered if the load conditions are expected to change during the CW. 
Table 1: Constant inflow concentrations used for simulations. These values were obtained from averages of an experimental study conducted in the pilot wetland [García et al., 2004]

\begin{tabular}{|l|l|l|l|}
\hline Componenet & Description & $\begin{array}{l}\text { Inflow concen- } \\
\text { tration }\end{array}$ & Unit \\
\hline$S_{O}$ & Dissolved oxygen & 0 & $\mathrm{mgCOD} \cdot L^{-1}$ \\
\hline$S_{F}$ & Soluble fermentable COD & 39 & $\mathrm{mgCOD} \cdot L^{-1}$ \\
\hline$S_{A}$ & $\begin{array}{l}\text { Fermentation products as ac- } \\
\text { etate as COD }\end{array}$ & 52 & $\mathrm{mgCOD} \cdot \mathrm{L}^{-1}$ \\
\hline$S_{I}$ & Inert soluble COD & 13 & $\mathrm{mgCOD} \cdot L^{-1}$ \\
\hline$X_{S m}$ & $\begin{array}{l}\text { Aqueous slowly biodegradable } \\
\text { particulate COD }\end{array}$ & 130 & $\mathrm{mgCOD} \cdot L^{-1}$ \\
\hline$X_{S f}$ & $\begin{array}{l}\text { Solid slowly biodegradable par- } \\
\text { ticulate COD }\end{array}$ & 0 & $\mathrm{mgCOD} \cdot L^{-1}$ \\
\hline$X_{I m}$ & Aqueous inert particulate COD & 26 & $\mathrm{mgCOD} \cdot L^{-1}$ \\
\hline$X_{f}$ & Solid inert particulate COD & 0 & $\mathrm{mgCOD} \cdot L^{-1}$ \\
\hline$S_{N O}{ }^{a}$ & Nitrite and nitrate nitrogen & 0 & $\mathrm{mgN} \cdot L^{-1}$ \\
\hline$S_{N H}$ & $\begin{array}{l}\text { Ammonium and ammonia nitro- } \\
\text { gen }\end{array}$ & 57 & $\mathrm{mgN} \cdot L^{-1}$ \\
\hline$S_{S O 4}$ & Sulphate sulphur & 72 & $\mathrm{mgS} \cdot L^{-1}$ \\
\hline$S_{H 2 S}$ & Hydrogen sulphide sulphur & 0 & $\mathrm{mgS} \cdot L^{-1}$ \\
\hline
\end{tabular}

${ }^{a}$ Note that $S_{N O}$ is assumed to include all nitrite and nitrate nitrogen, since nitrite is not included as a separate model component. 
Table 2: Organic and hydraulic overloads considered in each simulation

\begin{tabular}{|l|l|l|}
\hline Simulation & \% Organic overload & \% Hydraulic overload \\
\hline$S_{0}$ & 0 & 0 \\
\hline$S_{+10 \%}^{C}$ & 10 & 0 \\
\hline$S_{+30 \%}^{C}$ & 30 & 0 \\
\hline$S_{+30 \%}^{q}$ & 0 & 30 \\
\hline$S_{+15 \%+15 \%}^{C, q}$ & 15 & 15 \\
\hline
\end{tabular}




\section{References}

J. Puigagut, J. Villaseñor, J. Salas, E. Bécares, J. García, Subsurface-flow constructed wetlands in Spain for the sanitation of small communities: A comparative study, Ecological Engineering 30 (4) (2007) 312-319, ISSN 09258574.

F. Masi, N. Martinuzzi, R. Bresciani, L. Giovannelli, G. Conte, Tolerance to hydraulic and organic load fluctuations in constructed wetlands, Water Sci. Technol. 56 (3) (2007) 39-48, doi:10.2166/wst.2007.507.

G. M. P. R. Weerakoon, K. B. S. N. Jinadasa, G. B. B. Herath, M. I. M. Mowjood, J. J. a. van Bruggen, Impact of the hydraulic loading rate on pollutants removal in tropical horizontal subsurface flow constructed wetlands, Ecol. Eng. 61 (2013) 154-160, ISSN 09258574.

A. Galvão, J. Matos, Response of horizontal sub-surface flow constructed wetlands to sudden organic load changes, Ecological Engineering 49 (2012) 123-129, doi:10.1016/j.ecoleng.2012.08.033, URL http://dx.doi.org/10.1016/j.ecoleng.2012.08.033.

C. Ávila, J. García, M. Garfí, Influence of hydraulic loading rate, simulated storm events and seasonality on the treatment performance of an experimental three-stage hybrid constructed wetland system, Ecological Engineering 87 (2016) 324-332, doi:10.1016/j.ecoleng.2015.11.042.

E. Ojeda, J. Caldentey, M. Saaltink, J. García, Evaluation of relative importance of different microbial reactions on organic matter removal in horizontal subsurface-flow constructed wetlands using a 2D simulation model, Ecological Engineering 34 (1) (2008) 65-75, ISSN 09258574.

A. Caselles-Osorio, J. García, Performance of experimental horizontal subsurface flow constructed wetlands fed with dissolved or particulate organic matter., Water research 40 (19) (2006) 3603-11, ISSN 0043-1354.

A. Rizzo, G. Langergraber, A. Galvao, F. Boano, R. Revelli, L. Ridolfi, Modelling the response of laboratory horizontal flow constructed wetlands to unsteady organic loads with HYDRUS-CWM1, Ecol. Eng. 68 (2014) 209-213, ISSN 0925-8574, doi:10.1016/j.ecoleng.2014.03.073.

A. Rizzo, G. Langergraber, Novel insights on the response of horizontal flow constructed wetlands to sudden changes of influent organic load: A modeling study, Ecological Engineering 93 (2016) 242-249, doi: 10.1016/j.ecoleng.2016.05.071.

E. S. 12556-3, Small wastewater treatment systems up to 50 PT. Part 3: Packaged and/or site assembled domestic wastewater treatment plants, Tech. Rep., Osterreichisches Normungsinstitut, Vienna, Austria, 2005.

R. Samsó, J. García, BIO_PORE, a mathematical model to simulate biofilm growth and water quality improvement in porous media: Application and calibration for constructed wetlands, Ecol. Eng. 54 (2013a) 116-127, doi: 10.1016/j.ecoleng.2013.01.021.

R. Samsó, J. García, Bacteria distribution and dynamics in constructed wetlands based on modelling results, Sci. Total Environ. 461 (2013b) 430-440, ISSN 0048-9697, doi:10.1016/j.scitotenv.2013.04.073.

R. Samsó, J. García, The Cartridge Theory: A description of the functioning of horizontal subsurface flow constructed wetlands for wastewater treatment, based on modelling results, Sci. Total Environ. 473 (2014) 651-658, ISSN 0048-9697, doi:10.1016/j.scitotenv2013.12.070.

G. Langergraber, D. P. L. Rousseau, J. García, J. Mena, CWM1: a general model to describe biokinetic processes in subsurface flow constructed wetlands., Water Science \& Technology 59 (9) (2009) 1687-1697, ISSN 02731223.

D. J. Batstone, J. Keller, I. Angelidaki, S. V. Kalyuzhny, S. G. Pavlostathis, A. Rozzi, W. T. M. Sanders, H. Siegrist, V. A. Vavilin, Anaerobic digestion model No. 1 (ADM1), IWA Publishing, ISBN 1-900222-78-7, 2002.

M. Henze, W. Gujer, T. Mino, M. van Loosdrecht, Activated sludge models ASM1, ASM2, ASM2d and ASM3, IWA task group on mathematical modelling for design and operation of biological wastewater treatment, Tech. Rep., IWA scientific and technical report, 2000.

J. García, J. Chiva, P. Aguirre, E. Álvarez, J. Sierra, R. Mujeriego, Hydraulic behaviour of horizontal subsurface flow constructed wetlands with different aspect ratio and granular medium size, Ecol. Eng. 23 (3) (2004) 177-187, ISSN 0925-8574, doi:10.1016/j.ecoleng.2004.09.002.

R. Kadlec, S. Wallace, Treatment Wetlands, 2nd edition, CRC press, Boca Raton, FL, USA, ISBN 9781420012514, 2009.

N. Marleni, S. Gray, A. Sharma, S. Burn, N. Muttil, Impact of water management practice scenarios on wastewater flow and contaminant concentration, J. Environ. Manage. 151 (2015) 461-471, ISSN 0301-4797, doi: 10.1016/j.jenvman.2014.12.010. 